Research Article

\title{
Assessment of Knowledge regarding Polycystic Ovary Syndrome (PCOS) among Nursing Students
}

\author{
Saliqua Sehar
}

Tutor, Rufaida College of Nursing, Jamia Hamdard, New Delhi, India.

DOI: https://doi.org/10.24321/2455.9318.202025

\section{I $\quad \mathbf{N} \quad \mathbf{F} \quad \mathbf{O}$}

\section{E-mail Id:}

saliquasehar28@gmail.com

\section{Orcid Id:}

https://orcid.org/0000-0002-2074-6235

How to cite this article:

Sehar S. Assessment of Knowledge regarding Polycystic Ovary Syndrome (PCOS) among Nursing Students. Int I Nurs Midwif Res 2020; $7(3): 42-45$.

Date of Submission: 2020-12-27

Date of Acceptance: 2021-02-25

\section{$\begin{array}{lllllllllll}\mathbf{A} & \mathbf{B} & \mathbf{S} & \mathbf{T} & \mathbf{R} & \mathbf{A} & \mathbf{C} & \mathbf{T}\end{array}$}

Introduction: PCOS is most common non-communicable disease in females after hypertension and diabetes mellitus in India. Females with PCOS have a higher risk of developing health complications like infertility, HTN, abortion, insulin resistance etc. Lack of knowledge and poor lifestyle choices are considered to be the major factor leading to this syndrome. Nurses are in unique position to create awareness regarding this syndrome. Informed choices and lifestyle management like weight loss, stress management are key factors in management of this disease.

Objectives: The objective of the study was to assess the knowledge regarding PCOS (Polycystic Ovary Syndrome) among Nursing Students.

Methodology: The present study has used Quantitative Research Approach and Descriptive Research Design. A total 60 nursing students who were studying in DGNM $3^{\text {rd }}$ year and B.Sc. Hons Nursing $4^{\text {th }}$ year participated in the study. Data was gathered using demographic sheet and structured questionnaire which was administered through online mode after formal permission. Descriptive statistics such as frequency, percentage, means and median and standard deviation were used to describe the demographic profile and level of knowledge regarding PCOS.

Result: The study found that majority of Nursing Students (60\%) have average knowledge, $38.33 \%$ have Good knowledge and $1.66 \%$ have poor knowledge regarding Polycystic Ovary Syndrome.

Conclusion: The finding of the study indicates that the majority of the Nursing students had average knowledge regarding Polycystic Ovary Syndrome (PCOS).

Keywords: Nursing students, PCOS, Polycystic Ovary Syndrome, Knowledge

\section{Introduction}

Polycystic Ovary Syndrome (PCOS), referred to a condition in women characterized by irregular or no menstrual periods, acne, obesity, and excessive hair growth. PCOS may be a disorder of chronically abnormal ovarian function and hyperandrogenism (abnormally elevated androgen levels). 
It affects $5-10 \%$ of women of reproductive age. PCOS is also known as Stein-Leventhal syndrome as it was first described by Stein-Leventhal in 1935 . $^{1}$

Females with PCOS usually have less frequent menstrual periods. They have excess male hormone levels and formation of various small collections of fluid in ovary known as follicles and there may be ovulation failure also present. ${ }^{2}$ Insulin resistance and hyperinsulinemia is also frequently associated.

Worldwide estimation of prevalence of PCOS are highly variable, ranging from $2.2 \%$ to $26 \%$. Many studies done in some Asian countries using Rotterdam criteria among reproductive age group women has shown varied prevalence figures ranging from $2 \%$ to $7.5 \%$ in China to $6.38 \%$ in Srilanka. ${ }^{3}$

There is lack of data regarding prevalence of PCOD in India. Most prevalence studies in India are in hospital settings and most of them are observational studies done by clinicians. Recently few studies done among adolescents in schools report prevalence of PCOS as $9.13 \%$ to $36 \%$. ${ }^{4,5}$

Several studies suggest that one in every ten women in India has Polycystic Ovary Syndrome (PCOS), and out of every 10 females diagnosed with PCOS, six are teenage girls. ${ }^{6}$

The exact cause of PCOS is not known yet but studies suggest that genetic and environmental factors play a major role in the development of this hormonal imbalance. There are various endocrinologic abnormalities which usually are evident soon after menarche. The two most significant endocrinologic abnormalities are elevated Leutinizing Hormone (LH) and insulin resistance. Obesity is seen in $50 \%$ to $65 \%$ of PCOS patients. Obesity may have role in increasing the insulin resistance and hyperinsulinemia. ${ }^{7}$

The Endocrine Society advises to use the 2003 Rotterdam criteria for the diagnosis of PCOS. Although recommendations can vary across guidelines. Rotterdam criteria suggest that diagnosis of PCOS requires the presence of at least two of the following three findings: hyperandrogenism, ovulatory dysfunction and polycystic ovaries.

PCOS has long-term complications like type II diabetes, hypercholesterolemia, metabolic syndromes and heart conditions such as high blood pressure. ${ }^{8}$

Management of PCOS is a complex process as this syndrome affects multi-organs of the body. It should be individualized according to the presentation of the patient. Treatment of PCOS is not well understood but there are several ways to treat and manage the condition. Weight loss is considered as an effective method for treating the condition. It can be also be helpful in reduction of insulin resistance and hyperinsulinemia. It has been seen that weight loss alone can restore hormone level to normal. It can disappear or reduce many of the symptoms. Lifestyle modification is the major treatment for most of the manifestations. Increased physical activity and dietary modification are recommended for weight loss and cardiovascular risk reduction. Drugs like ovulation induction agents e.g. clomiphene is used to treat ovulation failure. Metformin is used to manage insulin resistance. Hormonal contraceptives are used to treat menstrual irregularities and hirsutism is managed with electrolysis and light based therapies and hormonal contraceptives etc. ${ }^{8}$

Nurses are in unique position to create awareness regarding this problem. Along with routine activities they can provide information to the women especially adolescent regarding PCOS and its management.

It has been observed that Female nursing students are also in their adolescence period and factors like poor lifestyle, stress etc can lead to PCOS among them. So, investigators thought that these nursing students can be helped by assessing their knowledge and that knowledge can be basis to provide necessary information in the future.

\section{Material and Method}

The present study has used quantitative research approach. The research design used for the study is descriptive research design. The study was conducted in Rufaida College of Nursing,New Delhi.The target population was B.Sc. Hons Nursing students and DGNM students. Sample were 60 nursing students who are studying in DGNM $3^{\text {rd }}$ year and B.Sc. Hons Nursing $4^{\text {th }}$ year. The study excluded the nursing students who were included in any other ongoing research. And who were not willing to participate. The present study used structured questionnaire to assess the knowledge regarding PCOS among nursing students. The tool was developed by the investigator by keeping in mind the objective of the study.

The tool was divided into two parts:

Section A: Demographic profile consisted of variables age, gender, religion, course of study, previous knowledge and sources of information.

Section B: Structured questionnaire which included questions to assess the knowledge regarding PCOS among nursing students. Content validity of the tool was done by 7 experts from the field of nursing. The researchers administered structured questionnaire through the online mode (Google form) to collect the data for assessing the knowledge of students regarding PCOS. There were 40 questions to assess the level of knowledge regarding PCOS. Each question had a score of one mark. Maximum score was 40 and minimum was 0 .

Pilot and final study was conducted after obtaining formal permission and consent of the participants. Confidentiality and anonymity was maintained of the participants. Collected data was analyzed using descriptive statistics. 


\section{Result}

The analyzed data are presented in various figures and tables.

Table 1, shows demographic characteristics of the participants .It revealed that majority of the participants $(81.7 \%)$ were female and $(18.3 \%)$ were male.Majority of the participants (60\%) were enrolled in B.Sc Nursing course followed by (40\%) in DGNM course.Majority of the students (95\%) were already having previous knowledge regarding Polycystic Ovary Syndrome followed by (5\%) who were not having knowledge regarding Polycystic Ovary Syndrome.

Table I.Frequency and percentage distribution of students according to their demographic characteristics

$(n=60)$

\begin{tabular}{|c|c|c|c|}
\hline $\begin{array}{l}\text { S. } \\
\text { No. }\end{array}$ & $\begin{array}{l}\text { Demographic } \\
\text { profile }\end{array}$ & Frequency & Percentage \\
\hline 1. & \multicolumn{3}{|c|}{ Age (in years) } \\
\hline & $17-21$ & 31 & $51.7 \%$ \\
\hline & $22-26$ & 29 & $48.3 \%$ \\
\hline & $27-31$ & 0 & $0 \%$ \\
\hline & $<31$ & 0 & $0 \%$ \\
\hline 2. & \multicolumn{3}{|c|}{ Gender } \\
\hline & Male & 11 & $18.3 \%$ \\
\hline & Female & 49 & $81.7 \%$ \\
\hline 3. & \multicolumn{3}{|c|}{ Religion } \\
\hline & Hinduism & 22 & $36.7 \%$ \\
\hline & Islamic & 32 & $53.3 \%$ \\
\hline & Christianity & 2 & $3.3 \%$ \\
\hline & Other & 4 & $6.7 \%$ \\
\hline 4. & \multicolumn{3}{|c|}{ Course of study } \\
\hline & B.Sc. $(H)$ Nursing & 36 & $60 \%$ \\
\hline & DGNM & 24 & $40 \%$ \\
\hline 5. & \multicolumn{3}{|c|}{ Previous knowledge } \\
\hline & Yes & 57 & $95 \%$ \\
\hline & No & 3 & $5 \%$ \\
\hline 6. & \multicolumn{3}{|c|}{ Source of information } \\
\hline & Family, Friends & 3 & $5 \%$ \\
\hline & $\begin{array}{c}\text { Books, Journals, } \\
\text { Internet }\end{array}$ & 33 & $55 \%$ \\
\hline & Medical personnel & 5 & $8.3 \%$ \\
\hline & Theory classes & 17 & $28.3 \%$ \\
\hline & Seminar/ Webinar & 2 & $3.4 \%$ \\
\hline
\end{tabular}

\section{Knowledge Score}

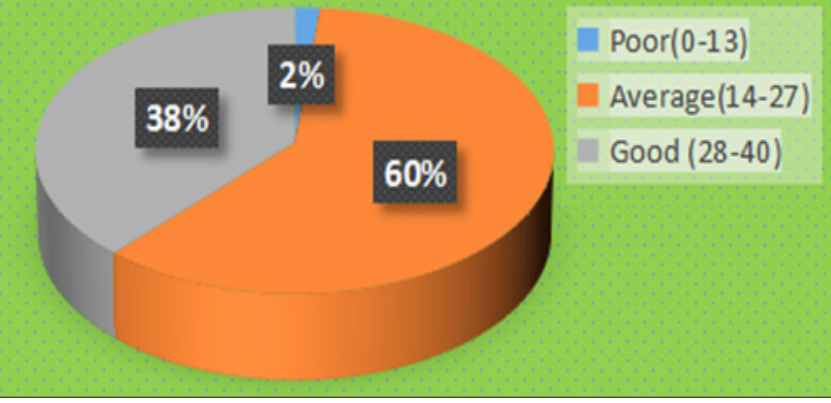

Figure I.Frequency and percentage distribution of knowledge score on polycystic ovary syndrome

Table 2.Range of order, mean, median, mode and standard deviation of the knowledge score

$(n=60)$

\begin{tabular}{|c|c|c|c|c|c|}
\hline Variable & $\begin{array}{c}\text { Range } \\
\text { of } \\
\text { order }\end{array}$ & $\begin{array}{c}\text { Me- } \\
\text { an }\end{array}$ & $\begin{array}{c}\text { Med- } \\
\text { ian }\end{array}$ & $\begin{array}{c}\text { Mo- } \\
\text { de }\end{array}$ & $\begin{array}{c}\text { Standard } \\
\text { deviation }\end{array}$ \\
\hline $\begin{array}{c}\text { Know- } \\
\text { ledge } \\
\text { Score }\end{array}$ & $13-39$ & 25.15 & 25 & 30 & 5.89 \\
\hline
\end{tabular}

\section{Discussion}

This study was aimed to estimate the knowledge of PCOS among nursing students. The study found that majority of nursing students (60\%) have average knowledge, $38.33 \%$ have good knowledge and $1.66 \%$ have poor knowledge regarding Polycystic Ovary Syndrome.

The findings are inconsistent and also they found that knowledge of the women with PCOS regarding PCOS and its management was found to be inadequate with the mean score of 12.1 out of $33 .^{9}$

The findings are consistent with the findings, who found that $76 \%$ of the samples were with average knowledge and $10.7 \%$ with good knowledge regarding Polycystic Ovarian Syndrome (PCOS). ${ }^{10}$

The present study is not congregant with the study, who found that samples were having poor knowledge on PCOS. Majority of nursing students (64.6\%) have never heard of PCOS before. Their mean Score was 0.28; which shows poor knowledge regarding PCOS. ${ }^{11}$

The findings are inconsistent with the findings, who found that almost all (100) students had inadequate knowledge regarding PCOS with the mean score of 14.97 out of $32 .{ }^{12}$ 


\section{Conclusion}

Student nurses should be educated about Polycystic Ovary Syndrome. The nurse acts as an advocate in helping the patient and family understanding the complexities of treatment decisions and manages the side effects of drugs and complications associated with PCOS. A well informed nurse can empower the patients with knowledge of the disease and treatment .It can have more positive influence on outcome of disease.

\section{Acknowledgment}

Authors would like to thanks to Mr. Umar, Mr. Hammad, Mr. Imran, Mr. Sadaab, Mr. Yousuf, Ms. Naveera, Ms. Neha, Ms. Nikita and Mr. Nouman.

\section{Conflicts of Interest: None \\ References}

1. Definition of Polycystic ovary syndrome. 2020. Available from: https://www.medicinenet.com/polycystic_ ovary_syndrome/definition.html.

2. Polycystic ovary syndrome (PCOS) - Symptoms and causes. 2020. Available from: https://www.mayoclinic. org/diseases-conditions/pcos/symptoms-causes/syc20353439.

3. Joshi B, Mukherjee S, Patil A et al. A cross-sectional study of polycystic ovarian syndrome among adolescent and young girls in Mumbai, India. Indian Journal of Endocrinology and Metabolism 2014; 18(3): 317.

4. Nidhi R, Padmalatha V, Nagarathna R et al. Prevalence of polycystic ovarian syndrome in Indian adolescents. Journal of Pediatric and Adolescent Gynecology 2011; 24(4): 223-7.

5. Nair M, Pappachan P, Balakrishnan S et al. Menstrual irregularity and poly cystic ovarian syndrome among adolescent girls - a 2 year follow-up study. The Indian Journal of Pediatrics 2011; 79(S1): 69-73.

6. Why PCOS is on the rise among Indian women. 2020. Available from: https://www.dailyo.in/variety/ polycystic-ovary-syndrome-womens-health/story/ 1/16785.html.

7. Polycystic Ovary Syndrome. Medscape. 2020. Available from: https://www.medscape.com/viewarticle /438597_2.

8. Williams T, Mortada R, Porter S. Diagnosis and treatment of polycystic ovary syndrome. 2020. Available from: https://www.aafp.org/afp/2016/0715/p106.html.

9. Dalal M, Babu M, Rastogi S. An exploratory survey to assess the knowledge, practice and prevalence of polycystic ovarian syndrome among women attending gyne OPD of selected hospital of Delhi with a view to develop a health care package on polycystic ovarian syndrome and its management. Journal of Nursing and Health Science 2014; 3(6): 39-42.
10. Sunanda B, Nayak S. A study to assess the knowledge regarding PCOS (Polycystic Ovarian Syndrome) among nursing students at NUINS. Journal of Health and Allied Sciences 2016; 6(3): 24-26.

11. Thomas A, Liew $Y$, Arena $M$ et al. Contributing factors and knowledge of polycystic ovarian syndrome (PCOS) among pre-clinical female students in FMHS, UNIMAS. Journal of Borneo Kalimantan 2017; 3(1).

12. Devi B, Bhutia K, Bhutia C. Knowledge regarding polycystic ovarian syndrome among students of selected nursing institute of Gangtok, East Sikkim. International Journal of Current Research 2017; 9(11): 61458-64. 